\title{
Correlation of Right Ventricular Wall Stress With Plasma B-Type Natriuretic Peptide Levels in Patients With Pulmonary Hypertension
}

\author{
Nami Uchiyama, MD; Toshinori Yuasa, MD, PhD; Masaaki Miyata, MD, PhD; \\ Yoshihisa Horizoe, MD; Hideto Chaen, MD, PhD; Kayoko Kubota, MD, PhD; \\ Kunitsugu Takasaki, MD, PhD; Naoko Mizukami, PhD; \\ Akira Kisanuki, MD, $\mathrm{PhD}$; Mitsuru Ohishi, $\mathrm{MD}, \mathrm{PhD}$
}

\begin{abstract}
Background: This study was designed to investigate the relationship between right ventricular wall stress (RVWS) and plasma B-type natriuretic peptide (BNP) levels in patients with pulmonary hypertension $(\mathrm{PH})$.

Methods and Results: The 57 consecutive PH patients and 8 control subjects were enrolled. Right heart catheterization (RHC), echocardiography, and BNP measurements were performed, and RVWS and left ventricular wall stress (LVWS) were calculated with the formula based on Laplace's law. Systolic RVWS and end-diastolic RVWS were higher in PH patients compared with controls (systolic RVWS: $77 \pm 41$ vs. $17 \pm 5$ kdynes $/ \mathrm{cm}^{2}(P<0.0001)$, end-diastolic RVWS: $15 \pm 12$ vs. $8 \pm 2 \mathrm{kdynes} / \mathrm{cm}^{2}(P<0.0005)$ ). Univariate analyses showed that logBNP at baseline correlated with systolic RVWS $(r=0.58, P<0.0001)$ and end-diastolic RVWS $(r=0.61$, $\mathrm{P}<0.0001$ ). We performed multivariate regression analysis and determined that end-diastolic RVWS was an independent determinant of logBNP in patients with PH. In addition, change in plasma BNP levels after treatment correlated with change in systolic RVWS $(r=0.70, P<0.0001)$ and change in end-diastolic RVWS $(r=0.68, P<0.0001)$.
\end{abstract}

Conclusions: Both systolic and end-diastolic RVWS were elevated in patients with $\mathrm{PH}$, and correlated with the symptoms of $\mathrm{PH}$. End-diastolic RVWS was an independent determinant of plasma BNP levels in $\mathrm{PH}$ patients.

Key Words: B-type natriuretic peptide; Pulmonary hypertension; Right ventricular wall stress

$\mathbf{O}$ ver recent decades numerous therapies have been developed to treat pulmonary hypertension $(\mathrm{PH})$, but an aggressive approach targeting multiple pathways in $\mathrm{PH}$ may lead to better treatment outcomes. ${ }^{1-5}$ The functional status of the right ventricle $(\mathrm{RV})$ remains the key determinant of prognosis, and the management of right heart failure (RHF) is essential for many PH patients, ${ }^{6,7}$ whose RV function can become impaired, even though pressure overload is reduced after $\mathrm{PH}$ treatment. ${ }^{7}$ The increased ventricular wall stress (WS) is the main determinant of changes to the ventricles, and reduction of right ventricular WS (RVWS) is an important treatment strategy for $\mathrm{PH}$ patients. ${ }^{8} \mathrm{WS}$ is a parameter related to the ventricular dimensions and pressure and is inversely proportional to wall thickness. WS cannot be measured directly, but its value can be estimated using the formula based on Laplace's law: $\mathrm{WS}=0.334 \times \mathrm{D} \times \mathrm{P} / \mathrm{WT}(1+\mathrm{WT} / \mathrm{D})$; where $\mathrm{D}=$ dimension,
$\mathrm{P}=$ pressure, and $\mathrm{WT}=$ wall thickness. $\mathrm{D}$ and $\mathrm{WT}$ are measured by echocardiography or magnetic resonance imaging (MRI), and $\mathrm{P}$ is determined by right heart catheterization (RHC). ${ }^{9}$ In the case of left ventricular (LV) disease, the LV end-diastolic WS correlates with plasma B-type natriuretic peptide (BNP) levels. ${ }^{10-13}$ BNP is a natriuretic hormone, used as a biomarker of RV dysfunction in patients with PH. ${ }^{14,15}$ Plasma BNP levels are associated with disease severity and exhibit a strong independent association with mortality rates in these patients; ${ }^{16,17}$ thus, the normalization of BNP levels has been suggested as a goal in PH treatment. ${ }^{18,19} \mathrm{BNP}$ is secreted from the ventricles in response to stretching of cardiac myocytes, and plasma BNP levels are demonstrated to be increased in LV and RV diseases. ${ }^{7}$ Previous studies reported the main stimulus of BNP secretion as cardiac WS in patients with LV disease, ${ }^{10,11,20,21}$ but no studies have investigated the association between RVWS

Received October 30, 2018; revised manuscript received February 22, 2019; accepted March 6, 2019; J-STAGE Advance Publication released online April 9, 2019 Time for primary review: 27 days

Department of Cardiovascular Medicine and Hypertension, Kagoshima University Graduate School of Medicine and Dental Sciences, Kagoshima (N.U., T.Y., M.M., Y.H., H.C., K.K., K.T., M.O.); Department of Clinical Laboratory, Kagoshima University Medical and Dental Hospital, Kagoshima (N.M.); and Department of Health Sciences, Kagoshima University Faculty of Medicine, Kagoshima University, Kagoshima (A.K.), Japan

Mailing address: Toshinori Yuasa, MD, PhD, Department of Cardiovascular Medicine and Hypertension, Kagoshima University, 8-35-1 Sakuragaoka, Kagoshima 890-8520, Japan. E-mail: yuasan@hotmail.com

ISSN-1346-9843 All rights are reserved to the Japanese Circulation Society. For permissions, please e-mail: cj@j-circ.or.jp 


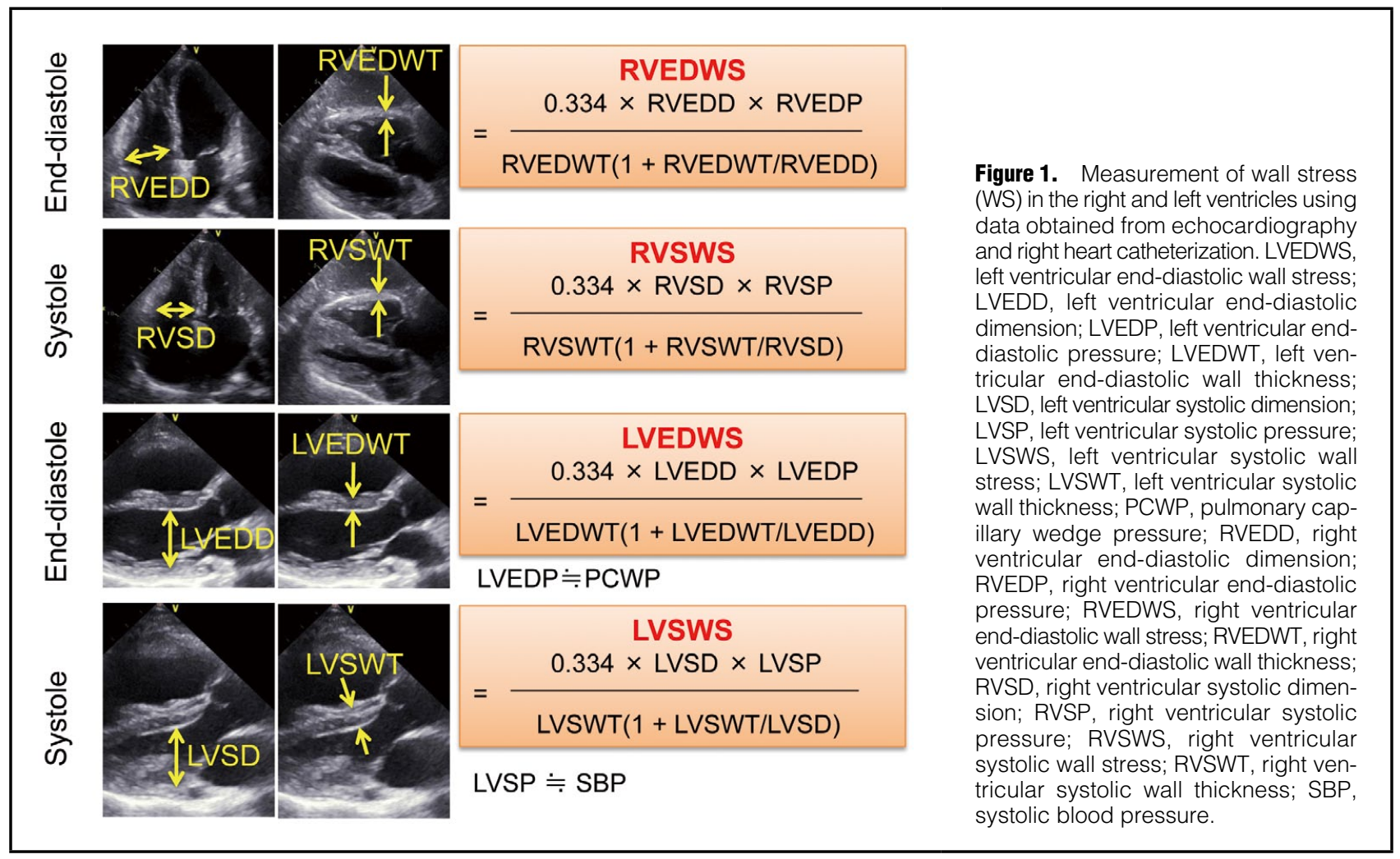

and BNP in patients with RV dysfunction caused by $\mathrm{PH}$. The purpose of the present study was to investigate the clinical significance of RVWS and to clarify the relationship between RVWS and BNP in patients with PH.

\section{Methods}

\section{Patients}

We enrolled 57 consecutive patients with $\mathrm{PH}$ diagnosed by RHC. Their mean pulmonary artery pressure (PAP) was $\geq 25 \mathrm{mmHg}$; they all underwent echocardiographic examinations. We set out the following exclusion criteria to avoid the influence of renal failure or left HF on BNP levels: a serum creatinine level $\geq 2.0 \mathrm{mg} / \mathrm{dL}, \mathrm{LV}$ ejection fraction $<50 \%$, and pulmonary capillary wedge pressure (PCWP) $\geq 15 \mathrm{mmHg}$. The control group comprised 8 subjects who were examined by echocardiography and RHC, and were cleared of cardiopulmonary disease as a result, and whose BNP levels were $<18 \mathrm{pg} / \mathrm{mL}$ and mean PAP was $<20 \mathrm{mmHg}$. The Ethics Committee of Kagoshima University unanimously approved this study, and informed consent was given by all patients.

\section{Measurement of Plasma BNP Levels}

Blood samples from the patients were obtained before performing the echocardiographic examination. Plasma BNP levels were measured using EDTA-plasma samples and a chemiluminescent enzyme immunoassay on the PATHFAST analyzer (Mitsubishi Chemical Medience Co., Tokyo, Japan).

\section{Echocardiographic Measurements}

Echocardiographic examinations were performed using the Vivid 7 or E9 (GE Healthcare, Tokyo, Japan) ultrasound systems, and the following parameters were measured

\begin{tabular}{|lc|}
\hline \multicolumn{2}{|l|}{ Table 1. Characteristics of the Study Patients With PH } \\
N (total) & PH group \\
Age (years) & 57 \\
Male & $60 \pm 15$ \\
Body mass index & $13(23)$ \\
BNP, pg/mL & $22.6 \pm 4.3$ \\
WHO functional class & $262 \pm 602$ \\
I & \\
II & $0(0)$ \\
III & $20(35)$ \\
IV & $25(44)$ \\
Type of PH & $12(21)$ \\
CTEPH & \\
CTD-PAH & $25(44)$ \\
IPAH & $20(35)$ \\
Other & $6(10)$ \\
Therapy & $6(10)$ \\
Balloon pulmonary angioplasty & \\
Anticoagulation & $23(40)$ \\
Diuretics & $29(51)$ \\
Vasodilator & $24(42)$ \\
Endothelin-receptor antagonist & \\
PDE-5 inhibitor & $26(46)$ \\
Beraprost & $21(37)$ \\
Epoprostenol & $16(28)$ \\
\hline
\end{tabular}

Values are mean $\pm \mathrm{SD}, \mathrm{n}(\%)$. CTD-PAH, connective tissue diseaseassociated pulmonary artery hypertension; CTEPH, chronic thromboembolic pulmonary hypertension; IPAH, idiopathic pulmonary artery hypertension; $\mathrm{PDE}-5$, phosphodiesterase type 5 ; $\mathrm{PH}$, pulmonary hypertension; WHO, World Health Organization. 


\begin{tabular}{|c|c|c|c|}
\hline & $\underset{(n=57)}{P H}$ & $\begin{array}{c}\text { Control } \\
(n=8)\end{array}$ & $P$ value \\
\hline Age (years) & $60 \pm 15$ & $65 \pm 8$ & NS \\
\hline Male & $13(23)$ & $4(50)$ & NS \\
\hline Body mass index & $22.6 \pm 4.3$ & $24.3 \pm 2.7$ & NS \\
\hline BNP $(p g / m L)$ & $262 \pm 602$ & $13 \pm 4$ & $<0.005$ \\
\hline \multicolumn{4}{|l|}{ Wall stress (kdynes/cm²) } \\
\hline Systolic RVWS & $77 \pm 41$ & $17 \pm 5$ & $<0.0001$ \\
\hline End-diastolic RVWS & $15 \pm 12$ & $8 \pm 2$ & $<0.0005$ \\
\hline Systolic LVWS & $63 \pm 22$ & $58 \pm 22$ & NS \\
\hline End-diastolic LVWS & $8 \pm 4$ & $6 \pm 1$ & NS \\
\hline \multicolumn{4}{|l|}{ Hemodynamic measurements } \\
\hline Systolic PAP (mmHg) & $61 \pm 18$ & $25 \pm 3$ & $<0.0001$ \\
\hline Mean PAP $(\mathrm{mmHg})$ & $37 \pm 10$ & $16 \pm 2$ & $<0.0001$ \\
\hline Systolic RVP (mmHg) & $60 \pm 18$ & $28 \pm 3$ & $<0.0001$ \\
\hline End-diastolic RVP (mmHg) & $8 \pm 4$ & $7 \pm 1$ & NS \\
\hline PCWP (mmHg) & $7 \pm 5$ & $8 \pm 3$ & NS \\
\hline Mean RAP (mmHg) & $5 \pm 4$ & $5 \pm 2$ & NS \\
\hline $\mathrm{CO}(\mathrm{L} / \mathrm{min})$ & $4.0 \pm 1.0$ & $4.7 \pm 0.8$ & $<0.05$ \\
\hline $\mathrm{SV}(\mathrm{mL})$ & $51 \pm 16$ & $69 \pm 13$ & $<0.01$ \\
\hline \multicolumn{4}{|c|}{ Echocardiographic measurements } \\
\hline Systolic RVD (mm) & $32 \pm 8$ & $14 \pm 5$ & $<0.0001$ \\
\hline End-diastolic RVD (mm) & $40 \pm 9$ & $21 \pm 4$ & $<0.0001$ \\
\hline Systolic RVWT (mm) & $7.3 \pm 1.6$ & $5.4 \pm 0.8$ & $<0.0001$ \\
\hline End-diastolic RVWT (mm) & $6.4 \pm 1.4$ & $4.9 \pm 0.8$ & $<0.0005$ \\
\hline RV FAC (\%) & $30 \pm 13$ & $42 \pm 13$ & $<0.05$ \\
\hline LVEF (\%) & $71 \pm 9$ & $65 \pm 9$ & NS \\
\hline TAPSE (mm) & $19 \pm 3$ & NA & \\
\hline $\operatorname{TR}$ PFV $(\mathrm{m} / \mathrm{s})$ & $3.6 \pm 0.7$ & $2.2 \pm 0.2$ & $<0.0001$ \\
\hline
\end{tabular}

Values are mean $\pm S D, n(\%)$. BNP, B-type natriuretic peptide; CO, cardiac output; FAC, fractional area change; LVEF, left ventricular ejection fraction; LVWS, left ventricular wall stress; NA, not available; NS, not significant; PAP, pulmonary arterial pressure; PCWP, pulmonary capillary wedge pressure; RAP, right atrial pressure; RVD, right ventricular dimension; RVP, right ventricular pressure; RVWS, right ventricular wall stress; RVWT, right ventricular wall thickness; SV, stroke volume; TAPSE, tricuspid annular plane systolic excursion; TR PFV, tricuspid regurgitation peak flow velocity.

according to the guidelines of the American Society of Echocardiography. ${ }^{22}$ Systolic RV dimension (RVD) and end-diastolic RVD, of which the basal cavity of the RV was measured in the apical RV-focused 4-chamber view in the systolic and end-diastolic periods. Systolic RVWT and enddiastolic RVWT, which were measured in the subcostal view or apical RV-focused 4-chamber view in the systolic and end-diastolic periods. For calculation of left ventricular WS (LVWS), systolic LV dimension (LVD), end-diastolic LVD, systolic LVWT, and end-diastolic LVWT were measured. For estimation of PH status and RV function, tricuspid regurgitation peak flow velocity (TR PFV), RV fractional area change (RV FAC), and tricuspid annular plane systolic excursion (TAPSE) were measured.

\section{Hemodynamic Examination}

RHC was performed after the echocardiographic examination to measure multiple variables: systolic PAP, diastolic PAP, mean PAP, pulmonary vascular resistance (PVR), systolic RV pressure (RVP), end-diastolic RVP, mean right atrial pressure (RAP), cardiac output (CO), stroke volume (SV), PCWP as a substitute for end-diastolic LV pressure (LVP), and systolic blood pressure (SBP) as a substitute for systolic LVP.

\section{Calculation of WS}

WS was calculated using the following formula based on Laplace's law: ${ }^{9} \mathrm{WS}=0.334 \times \mathrm{D} \times \mathrm{P} / \mathrm{WT}(1+\mathrm{WT} / \mathrm{D})$, where $\mathrm{D}=$ dimension, $\mathrm{P}=$ pressure, and $\mathrm{WT}=$ wall thickness. As shown in Figure 1, end-diastolic RVWS was calculated using basal end-diastolic RVD, end-diastolic RVWT, and end-diastolic RVP measured by RHC. Systolic RVWS was calculated using systolic RVD, systolic RVWT, and systolic RVP. End-diastolic left ventricular WS (LVWS) was calculated using end-diastolic LVD, end-diastolic LVWT, and PCWP as a substitute for end-diastolic LVP. Systolic LVWS was calculated using systolic LVD, systolic LVWT, and SBP as a substitute for systolic LVP. We then compared these $\mathrm{RV}$ and LV functional parameters with BNP levels.

\section{Reproducibility of Measurements}

Two independent observers repeated 10 measurements of systolic RVWS and end-diastolic RVWS to investigate the interobserver and intraobserver differences. Differences in the measurements by the 2 observers were obtained to estimate interobserver variability. The same observer repeated the 10 measurements, and intraobserver variability was calculated. 


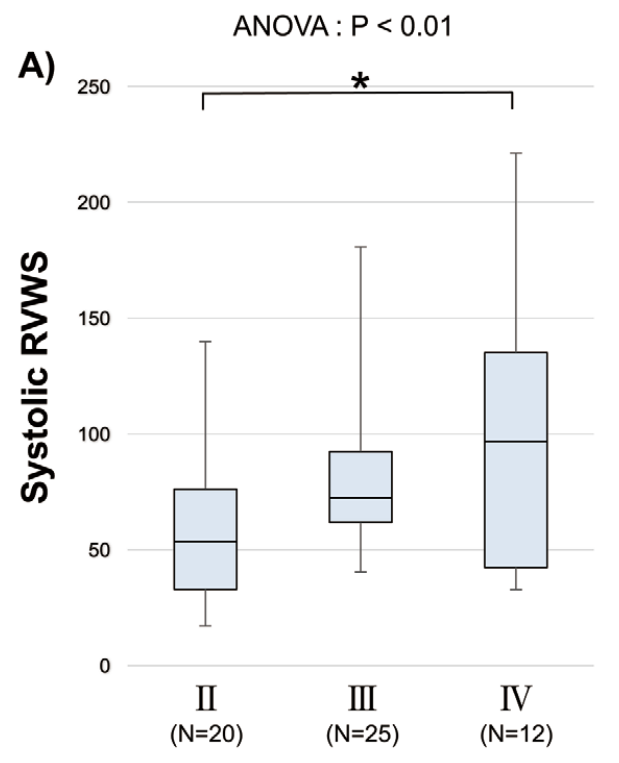

WHO functional class

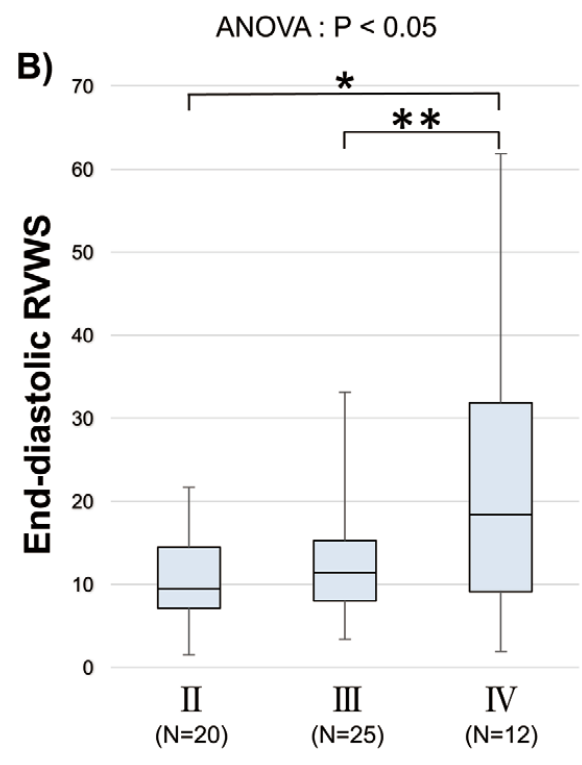

WHO functional class

Figure 2. Relationship between WHO functional class and RVWS. Systolic RVWS (A) and end-diastolic RVWS (B) are presented as box (25th percentile, median, 75th percentile) and whisker (10th and 90th percentiles) plots. ${ }^{*} \mathrm{P}<0.05$ vs. WHO class $\|$, ${ }^{* *} \mathrm{P}<0.05$ vs. ANOVA, analysis of variance; WHO class III. RVWS, right ventricular wall stress; WHO, World Health Organization.

\section{Statistical Analysis}

Data are expressed as mean $\pm \mathrm{SD}$ or median (interquartile range) as appropriate. Comparisons between the $\mathrm{PH}$ group and controls were performed using Student's t-test. BNP levels were $\log$-transformed $(\log \mathrm{BNP})$ to obtain a normal distribution. Comparisons of parameters among 3 groups (WHO functional classes II, III and IV) were performed using analysis of covariance (ANOVA) followed by TukeyKramer's HSD post hoc test. The relationships between $\operatorname{logBNP}$ and RV measurements (RVWS, echocardiographic measurements, and RHC data) were analyzed with simple linear regression analyses. Determinants of $\log \mathrm{BNP}$ and BNP changes after treatment $(\triangle \mathrm{BNP})$ were explored by multiple stepwise regression analyses. All statistical analyses were performed with JMP version 6 (SAS Institute, Cary NC, USA). A P-value $<0.05$ was considered to be statistically significant.

\section{Results}

\section{Patients' Characteristics}

The patients' characteristics are summarized in Table 1. The mean age of the patients was $60 \pm 15$ years, and 13 patients $(23 \%)$ were male; all patients were diagnosed as having $\mathrm{PH}$ by RHC studies. The subtypes of $\mathrm{PH}$ in these patients were: chronic thromboembolic PH (CTEPH: 44\%), connective tissue disease-associated PH (CTDAPH: 35\%), idiopathic pulmonary artery hypertension (10\%), and others $(10 \%)$; 34 patients $(60 \%)$ were de novo patients at baseline who were diagnosed as having $\mathrm{PH}$ for the first time. The mean BNP level was $262 \pm 602 \mathrm{pg} / \mathrm{mL}$. After measurements at baseline, the $\mathrm{PH}$ patients had the following therapies: balloon pulmonary angioplasty for CTEPH (40\%), anticoagulation $(51 \%)$, diuretics $(42 \%)$, endothelin-receptor antagonist (46\%), phosphodiesterase type 5 inhibitor (37\%), beraprost $(28 \%)$, and epoprostenol $(16 \%)$.

\section{Comparison of RVWS Between PH Patients and Controls}

As shown in Table 2, we compared RVWS, LVWS, echocardiographic measurements and cardiac hemodynamic values between the $\mathrm{PH}$ and control groups. Both systolic RVWS and end-diastolic RVWS were higher in $\mathrm{PH}$ patients compared with controls (systolic RVWS: 77 \pm 41 vs. $17 \pm 5 \mathrm{kdynes} / \mathrm{cm}^{2}(\mathrm{P}<0.0001)$, end-diastolic RVWS: $15 \pm 12$ vs. $\left.8 \pm 2 \mathrm{kdynes} / \mathrm{cm}^{2}(\mathrm{P}<0.0005)\right)$. As compared with controls, the PH group showed significant increased systolic PAP or RVP, enlarged RV dimensions, increased RVWT and decreased RV FAC.

\section{RVWS and WHO Functional Class}

To determine the relationship between the functional status of PH and RVWS, the relationships between RVWS and WHO functional class of $\mathrm{PH}$ patients were assessed by ANOVA and Tukey-Kramer's HSD post hoc test. Figure 2 shows that both systolic and end-diastolic RVWS increased significantly with worsening WHO functional class (systolic RVWS: $\mathrm{P}<0.01$, end-diastolic RVWS: $\mathrm{P}<0.05$ ). Systolic RVWS in patients with WHO class IV was significantly higher than in patients with WHO class II (Figure 2A). End-diastolic RVWS in patients with WHO class IV was significantly higher than in patient with WHO class II or III (Figure 2B).

\section{Relationship Between LogBNP and RVWS at Baseline}

To investigate the determinants of plasma BNP levels in patients with $\mathrm{PH}$, we analyzed the correlation between logBNP and various parameters (Table 3). Univariate analyses demonstrated that $\log \mathrm{BNP}$ at baseline positively correlated 


\begin{tabular}{|c|c|c|c|}
\hline & \multicolumn{2}{|c|}{ Univariate } & \multirow{2}{*}{$\frac{\text { Multivariate }}{P \text { value }}$} \\
\hline & $\mathbf{R}$ & $P$ value & \\
\hline Age & 0.23 & 0.09 & \\
\hline Male & 0.06 & 0.65 & \\
\hline Body weight & -0.11 & 0.43 & \\
\hline Body mass index & -0.14 & 0.30 & \\
\hline $\mathrm{Hb}$ & -0.04 & 0.75 & \\
\hline $\mathrm{Cr}$ & -0.09 & 0.49 & \\
\hline \multicolumn{4}{|l|}{ Wall stress } \\
\hline Systolic RVWS & 0.58 & $<0.0001$ & 0.086 \\
\hline End-diastolic RVWS & 0.61 & $<0.0001$ & 0.0008 \\
\hline Systolic LVWS & 0.03 & 0.80 & \\
\hline End-diastolic LVWS & -0.06 & 0.68 & \\
\hline \multicolumn{4}{|c|}{ Hemodynamic measurements } \\
\hline Systolic PAP & 0.45 & $<0.0005$ & 0.94 \\
\hline End-diastolic PAP & 0.45 & $<0.0005$ & 0.31 \\
\hline Systolic RVP & 0.44 & $<0.001$ & 0.70 \\
\hline End-diastolic RVP & 0.51 & $<0.0001$ & 0.85 \\
\hline PVR & 0.43 & $<0.001$ & 0.15 \\
\hline PCWP & 0.11 & 0.43 & \\
\hline Mean RAP & 0.44 & $<0.0001$ & 0.86 \\
\hline $\mathrm{CO}$ & -0.32 & $<0.05$ & 0.64 \\
\hline SV & -0.36 & $<0.01$ & 0.17 \\
\hline \multicolumn{4}{|c|}{ Echocardiographic measurements } \\
\hline Systolic RVWT & -0.05 & 0.71 & \\
\hline End-diastolic RVWT & 0.06 & 0.88 & \\
\hline Systolic RVD & 0.54 & $<0.0001$ & 0.43 \\
\hline End-diastolic RVD & 0.41 & $<0.005$ & 0.39 \\
\hline RVFAC & -0.23 & 0.082 & \\
\hline TAPSE & -0.086 & 0.53 & \\
\hline
\end{tabular}

$\mathrm{Cr}$, serum creatinine; $\mathrm{Hb}$, hemoglobin concentration; PVR, pulmonary vascular resistance; RVFAC, right ventricular fractional area change. Other abbreviations as in Table 2.
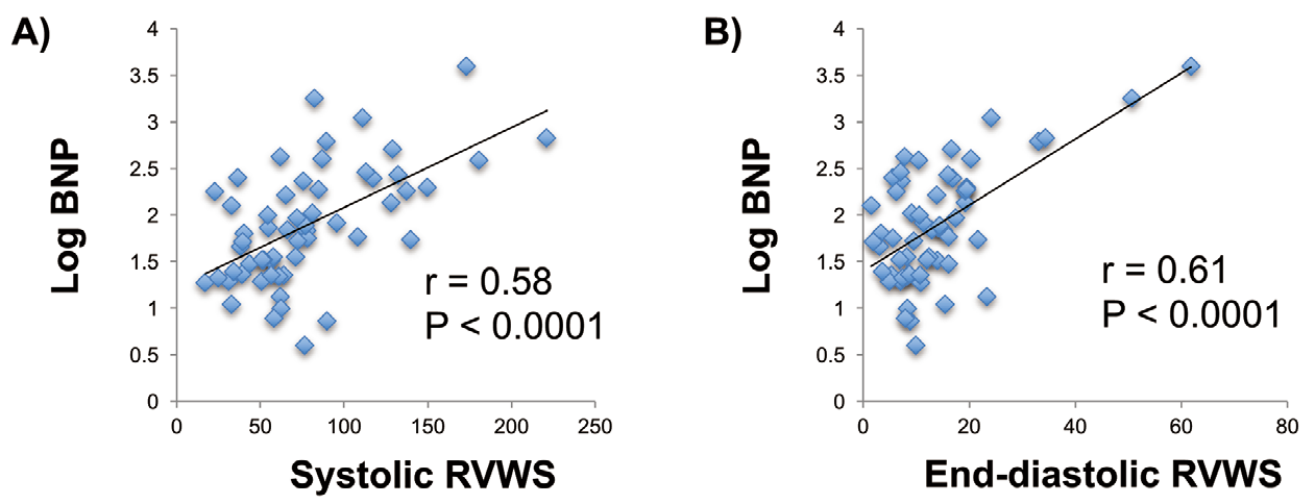

Figure 3. Correlation between logBNP and systolic RVWS (A) or end-diastolic RVWS (B). BNP, B-type natriuretic peptide; RVWS, right ventricular wall stress.

with systolic RVWS ( $\mathrm{r}=0.58, \mathrm{P}<0.0001)$, end-diastolic RVWS ( $r=0.61, \mathrm{P}<0.0001)$, systolic $\mathrm{PAP}(\mathrm{r}=0.45, \mathrm{P}<0.0005)$, end-diastolic PAP $(r=0.45, \mathrm{P}<0.0005)$, systolic $\mathrm{RVP}(\mathrm{r}=0.44$, $\mathrm{P}<0.001)$, end-diastolic RVP $(\mathrm{r}=0.51, \mathrm{P}<0.0001)$, PVR $(r=0.43, \mathrm{P}<0.001)$, mean RAP $(r=0.44, \mathrm{P}<0.0005)$, systolic
$\mathrm{RVD}(\mathrm{r}=0.54, \mathrm{P}<0.0001)$, and end-diastolic $\mathrm{RVD}(\mathrm{r}=0.41$, $\mathrm{P}<0.005)$ and was negatively correlated with $\mathrm{CO}(\mathrm{r}=-0.32$, $\mathrm{P}<0.05)$ and $\mathrm{SV}(\mathrm{r}=-0.36, \mathrm{P}<0.01)$. However, $\log \mathrm{BNP}$ did not correlate with the following variates: age, sex (male), body weight, body mass index, hemoglobin concentration 


\begin{tabular}{|c|c|c|c|}
\hline \multirow[b]{3}{*}{ Wall stress } & \multicolumn{2}{|c|}{ Univariate } & \multirow{2}{*}{$\frac{\text { Multivariate }}{P \text { value }}$} \\
\hline & $\mathbf{R}$ & $P$ value & \\
\hline & & & \\
\hline$\Delta$ Systolic RVWS & 0.70 & $<0.0001$ & $<0.01$ \\
\hline$\Delta$ End-diastolic RVWS & 0.68 & $<0.0001$ & $<0.005$ \\
\hline$\Delta$ Systolic LVWS & -0.10 & 0.51 & \\
\hline$\Delta$ End-diastolic LVWS & -0.003 & 0.98 & \\
\hline \multicolumn{4}{|c|}{ Hemodynamic measurements } \\
\hline$\Delta$ Systolic PAP & 0.58 & $<0.0001$ & 0.75 \\
\hline$\Delta$ End-diastolic PAP & 0.54 & $<0.0005$ & 0.18 \\
\hline$\Delta$ Systolic RVP & 0.62 & $<0.0001$ & 0.40 \\
\hline$\Delta$ End-diastolic RVP & 0.60 & $<0.0001$ & 0.89 \\
\hline$\Delta \mathrm{PVR}$ & 0.58 & $<0.0001$ & 0.06 \\
\hline$\triangle \mathrm{PCWP}$ & 0.15 & 0.33 & \\
\hline$\Delta$ Mean RAP & 0.47 & $<0.005$ & 0.70 \\
\hline$\Delta \mathrm{CO}$ & -0.06 & 0.67 & \\
\hline$\Delta S V$ & -0.25 & 0.10 & \\
\hline \multicolumn{4}{|c|}{ Echocardiographic measurements } \\
\hline$\Delta$ Systolic RVD & 0.54 & $<0.0001$ & 0.93 \\
\hline$\Delta$ End-diastolic RVD & 0.43 & $<0.005$ & 0.10 \\
\hline$\Delta$ Systolic RVWT & 0.03 & 0.86 & \\
\hline$\Delta$ End-diastolic RVWT & 0.10 & 0.52 & \\
\hline
\end{tabular}

Aabbreviations as in Tables 2,3.

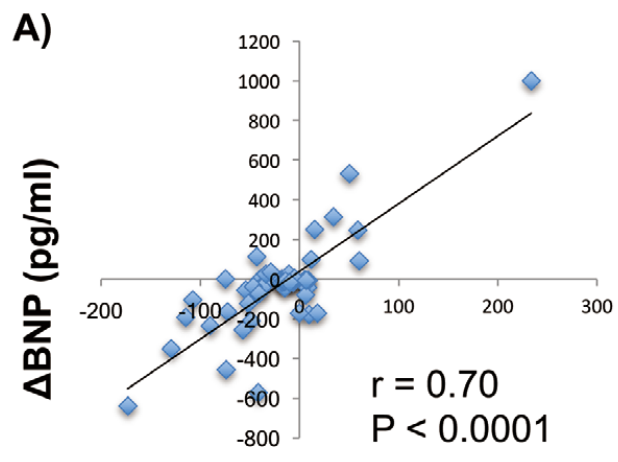

$\Delta$ Systolic RVWS

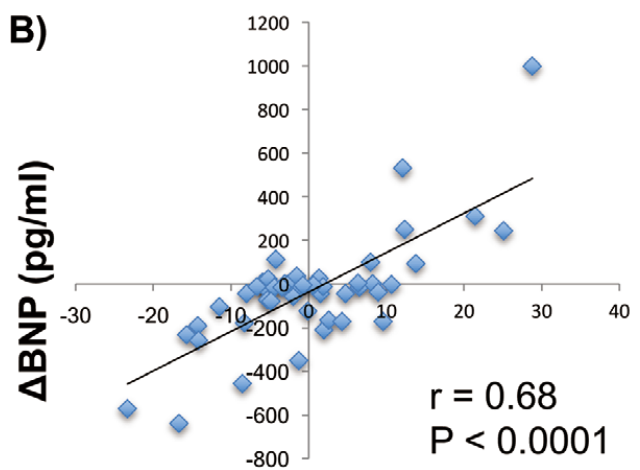

$\Delta$ End-diastolic RVWS

Figure 4. Correlation between changes in BNP and (A) change in systolic RVWS and (B) end-diastolic RVWS. BNP, B-type natriuretic peptide; RVWS, right ventricular wall stress.

and serum creatinine. Figure 3 shows that there was a good correlation between $\operatorname{logBNP}$ and systolic or end-diastolic RVWS. Multivariate regression analysis identified that end-diastolic RVWS was an independent determinant of $\log \mathrm{BNP}$.

\section{Relationship Between Changes in BNP Levels and RVWS}

Furthermore, to investigate the association of BNP levels with WS and hemodynamic or echocardiographic data, we analyzed changes in these parameters in 45 patients who underwent echocardiography and RHC before and after PH treatment (Table 4). Univariate analyses showed that $\triangle \mathrm{BNP}$ correlated with $\Delta$ systolic RVWS $(\mathrm{r}=0.70, \mathrm{P}<0.0001)$, $\Delta$ end-diastolic RVWS ( $\mathrm{r}=0.68, \mathrm{P}<0.0001), \Delta$ systolic PAP $(\mathrm{r}=0.58, \mathrm{P}<0.0001), \Delta$ end-diastolic $\mathrm{PAP}(\mathrm{r}=0.54, \mathrm{P}<0.0005)$, $\Delta$ systolic RVP $(\mathrm{r}=0.62, \mathrm{P}<0.0001), \Delta$ end-diastolic RVP $(\mathrm{r}=0.60, \mathrm{P}<0.0001), \Delta \mathrm{PVR}(\mathrm{r}=0.58, \mathrm{P}<0.0001), \Delta$ mean RAP $(\mathrm{r}=0.47, \mathrm{P}<0.005), \Delta$ systolic $\mathrm{RVD}(\mathrm{r}=0.54, \mathrm{P}<0.0001)$, and $\Delta$ end-diastolic RVD $(r=0.43, P<0.005)$. As shown in Figure 4, there was an excellent correlation between $\triangle \mathrm{BNP}$ and $\Delta$ systolic RVWS $(\mathrm{r}=0.70, \mathrm{P}<0.0001)$ or $\Delta$ end-diastolic RVWS $(r=0.68, P<0.0001)$. Multivariate regression analysis showed that $\Delta$ systolic RVWS and $\Delta$ end-diastolic RVWS were independent contributors to $\triangle \mathrm{BNP}$. 


\section{Reproducibility of Measurements}

The mean differences in interobserver and intraobserver variability for the measurement of systolic RVWS and enddiastolic RVWS were: systolic RVWS: $10.6 \pm 8.1$ or $6.6 \pm 7.8 \%$; end-diastolic RVWS: $8.4 \pm 4.1$ or $5.8 \pm 3.5 \%$.

\section{Discussion}

The main findings of this study were that BNP elevation correlated with an increase in end-diastolic RVWS, and that RVWS was valuable as a RV-specific parameter to evaluate RV loading conditions.

\section{RVWS as a Parameter of RV Loading Conditions}

Norton ${ }^{23}$ reviewed definitions of preload and afterload using Laplace's law. The term "preload" can be defined as all factors that contribute to passive ventricular WS at the end of diastole, and the term "afterload" can be defined as all the factors that contribute to total myocardial WS during systolic ejection. Opie and Bers state that preload is often estimated by end-diastolic pressure (EDP), but it is important to remember that the relationship between EDP and end-diastolic volume (EDV) varies between patients. ${ }^{24}$ This concept would be more important in $\mathrm{RV}$ evaluation that with the LV, because the RV is highly sensitive to changes in afterload, and a minor increase in afterload causes RV enlargement. End-diastolic RVWS can directly reflect both RVEDP and -EDV, so might be a more suitable parameter to assess RV preload compared with RVEDP or -EDV.

\section{RVWS in PH Patients}

In the early stages of $\mathrm{PH}$, the RV adapts to the increased PAP by increasing WT to maintain CO. In this compensated phase, RVWS remains normal or is reduced and patients feel few symptoms. Continued pressure overload induces changes in the RV pressure-volume relationship and the increase in RVWS. Finally, in the end stage, the RV dilates, which leads to further increase in RVWS. 25,26 Increased RVWS negatively affects myocardial perfusion, ${ }^{27}$ glucose metabolism, ${ }^{28}$ and myocardial oxygen consumption. ${ }^{29,30} \mathrm{RVWS}$ is key to progression of RHF, ${ }^{8}$ so evaluation of RVWS is important to assess RV loading conditions in patients with $\mathrm{PH}$.

\section{Measurement of RVWS}

RVWS has been estimated using MRI and RHC in patients with $\mathrm{PH} .{ }^{31,32}$ One study demonstrated that systolic RVWS was significantly higher in patients with idiopathic pulmonary artery hypertension than in controls and that it negatively correlated with the RV EF. ${ }^{31}$ Another study demonstrated that end-diastolic RVWS significantly decreased after pulmonary endarterectomy in patients with chronic thromboembolic $\mathrm{PH} .{ }^{32}$ Further, RVWS can be calculated using echocardiography and RHC and enddiastolic WS correlates with the right atrium size in patients with right-sided congenital heart disease. ${ }^{9}$ We used the same method to measure RVWS using echocardiography and RHC. The RV has a complex shape, so its linear dimensions are dependent on probe rotation and different RV views. $\mathrm{RVD}$ measurements in the apical RV-focused 4-chamber view are recommended to avoid underestimation. ${ }^{22}$ MRI might be more accurate for measuring RV geometry, but it is expensive and not always available. ${ }^{33}$ In contrast, the measurement of WS using echocardiography is simpler and a more accepted method compared with MRI; it can be used for frequent evaluations in patients with $\mathrm{PH}$.

\section{Correlation Between WS and BNP}

In LV disease, previous studies have reported the relationship between WS and BNP. Wiese et al demonstrated that in isolated atrial and ventricular human myocardium, diastolic overstretch increases BNP gene expression. ${ }^{34}$ Iwanaga et al reported that plasma BNP levels strongly correlate with end-diastolic LVWS, not only in patients with systolic HF but also in those with diastolic HF.11 To our knowledge, no studies have reported a correlation between RVWS and BNP levels. Ours is the first study to demonstrate a good correlation between RVWS and BNP levels. BNP levels can supplement clinical diagnosis of RHF caused by $\mathrm{PH}$, although BNP is a relatively nonspecific biomarker of RV. BNP levels are also higher in patients with LV dysfunction, renal failure, atrial arrhythmia, and so on. On the other hand, RVWS is a RV-specific parameter, and would be useful even for those patients in whom it is not possible to measure BNP. Our results suggested that RVWS was a key factor in BNP secretion, and that estimation of RVWS might be useful for evaluating RV loading conditions in patients with $\mathrm{PH}$.

\section{Study Limitations}

First, our study population was not very large, and we did not investigate the correlation between RVWS and BNP levels in each subtype of PH. Therefore, further large studies are needed to confirm our findings and determine the specific relationship between RVWS and BNP levels in each subtype of PH. Second, as the present study was limited to right $\mathrm{HF}$ caused by $\mathrm{PH}$, our results cannot be expanded to patients with biventricular HF, in which the major factor in the BNP level is the LV myocardium.

\section{Conclusions}

We demonstrated the significance of RVWS measured by echocardiography and RHC in PH patients. Both the systolic and end-diastolic RVWS were associated with the symptoms of $\mathrm{PH}$, and the end-diastolic RVWS was well correlated with plasma BNP levels. RVWS might be a useful parameter to evaluate RV loading conditions in patients with $\mathrm{PH}$.

\section{Acknowledgments}

We express our appreciation to the staff of the Department of Cardiovascular Medicine and Hypertension for their assistance with data processing. We also thank the ultrasonographers of Kagoshima University Hospital for their technical expertise in obtaining echocardiographic images.

\section{Disclosures}

The authors have no conflicts of interest to disclose.

\section{References}

1. Sitbon O, Gaine S. Beyond a single pathway: Combination therapy in pulmonary arterial hypertension. Eur Respir Rev 2016; 142: $408-417$.

2. Galiè N, Corris PA, Frost A, Girgis RE, Granton J, Jing ZC, et al. Updated treatment algorithm of pulmonary arterial hypertension. J Am Coll Cardiol 2013; 62: D60-D72.

3. Ogawa A, Satoh T, Fukuda T, Sugimura K, Fukumoto Y, Emoto $\mathrm{N}$, et al. Balloon pulmonary angioplasty for chronic thromboembolic pulmonary hypertension results of a multicenter registry. Circ Cardiovasc Qual Outcomes 2017; 10: e004029. 
4. Kaymaz C, Mutlu B, Küçükoğlu MS, Kaya B, Akdeniz B, Kılıçkıran Avcı B, et al. Preliminary results from a nationwide adult cardiology perspective for pulmonary hypertension: Registry on clinical outcome and survival in pulmonary hypertension groups (SIMURG). Anatol J Cardiol 2017; 18: 242-250.

5. Sitbon O, Noordegraaf AV. Epoprostenol and pulmonary hypertension: 20 years of clinical experience. Eur Respir Rev 2017; 26: 160055 .

6. McLaughlin VV, Shah SJ, Souza R, Humbert M. Management of pulmonary arterial hypertension. J Am Coll Cardiol 2015; 65: $1976-1997$.

7. van de Veerdonk MC, Kind T, Marcus JT, Mauritz GJ, Heymans MW, Bogaard HJ, et al. Progressive right ventricular dysfunction in patients with pulmonary arterial hypertension responding to therapy. J Am Coll Cardiol 2011; 58: 2511-2519.

8. Westerhof BE, Saouti N, van der Laarse WJ, Westerhof N, Vonk Noordegraaf A. Treatment strategies for the right heart in pulmonary hypertension. Cardiovasc Res 2017; 113: 1465-1473.

9. Addetia K, Sebag IA, Marelli A, Do DH, Afilalo J, Martucci G, et al. Right ventricular end-diastolic wall stress: Does it impact on right atrial size, and does it differ in right ventricular pressure vs. volume loading conditions? Can J Cardiol 2013; 29: 858-865.

10. Vanderheyden M, Goethals M, Verstreken S, De Bruyne B, Muller $\mathrm{K}$, Van Schuerbeeck E, et al. Wall stress modulates brain natriuretic peptide production in pressure overload cardiomyopathy. J Am Coll Cardiol 2004; 44: 2349-2354.

11. Iwanaga Y, Nishi I, Furuichi S, Noguchi T, Sase K, Kihara Y, et al. B-type natriuretic peptide strongly reflects diastolic wall stress in patients with chronic heart failure. J Am Coll Cardiol 2006; 47: $742-748$.

12. Niizuma S, Iwanaga $Y$, Yahata T, Tanaki Y, Goto Y, Nakahama $\mathrm{H}$, et al. Impact of left ventricular end-diastolic wall stress on plasma B-Type natriuretic peptide in heart failure with chronic kidney disease and end-stage renal disease. Clin Chem 2009; 55: $1347-1353$.

13. Maeder MT, Mariani JA, Kaya DM. Hemodynamic determinants of myocardial b-type natriuretic peptide release relative contributions of systolic and diastolic wall stress. Hypertension 2010; 56: 682-689.

14. Nagaya N, Nishikimi T, Okano Y, Uematsu Uematsu M, Satoh $\mathrm{T}$, Kyotani S, et al. Plasma brain natriuretic peptide levels increase in proportion to the extent of right ventricular dysfunction in pulmonary hypertension. $J$ Am Coll Cardiol 1998; 31: 202-208.

15. Tulevski II, Groenink M, van Der Wall EE, van Veldhuisen DJ, Boomsma F, Stoker J, et al. Increased brain and atrial natriuretic peptides in patients with chronic right ventricular pressure overload: Correlation between plasma neurohormones and right ventricular dysfunction. Heart 2001; 86: 27-30.

16. Nagaya N, Nishikimi T, Uematsu M, Satoh T, Kyotani S, Sakamaki F, et al. Plasma brain natriuretic peptide as a prognostic indicator in patients with primary pulmonary hypertension. Circulation 2000; 102: 865-870.

17. Benza RL, Miller DP, Gomberg-Maitland M, Frantz RP, Foreman AJ, Coffey CS, et al. Predicting survival in pulmonary arterial hypertension: Insights from the Registry to Evaluate Early and Long-Term Pulmonary Arterial Hypertension Disease Management (REVEAL). Circulation 2010; 122: 164-172.

18. McLaughlin VV, Gaine SP, Howard LS, Leuchte HH, Mathier MA, Mehta S, et al. Treatment goals of pulmonary hypertension. J Am Coll Cardiol 2013; 62: D73-D81.

19. Galiè N, Humbert M, Vachiery JL, Gibbs S, Lang I, Torbicki A,et al. Guidelines for the diagnosis and treatment of pulmonary hypertension: 2015 ESC/ERS Guidelines for the diagnosis and treatment of pulmonary hypertension: The Joint Task Force for the Diagnosis and Treatment of Pulmonary Hypertension of the European Society of Cardiology (ESC) and the European Respiratory Society (ERS): Endorsed by: Association for European Paediatric and Congenital Cardiology (AEPC), International Society for Heart and Lung Transplantation (ISHLT). Eur Heart $J$ 2016; 37: 67-119.

20. Panagopoulou V, Deftereos S, Kossyvakis C, Raisakis K, Giannopoulos G, Bouras G, et al. NTproBNP: An important biomarker in cardiac diseases. Curr Top Med Chem 2013; 13: $82-94$.

21. de Denus S, Pharand C, Williamson DR. Brain natriuretic peptide in the management of heart failure: The versatile neurohormone. Chest 2004; 125: 652-668.

22. Rudski LG, Lai WW, Afilalo J, Hua L, Handschumacher MD, Chandrasekaran K, et al. Guidelines for the echocardiographic assessment of the right heart in adults: A report from the American Society of Echocardiography endorsed by the European Association of Echocardiography, a registered branch of the European Society of Cardiology, and the Canadian Society of Echocardiography. J Am Soc Echocardiogr 2010; 23: 685-713.

23. Norton JM. Toward consistent definitions for preload and afterload. Adv Physiol Educ 2001; 25: 53-61.

24. Opie LH, Bers DM. Mechanism of cardiac contraction and relaxation. In: Mann DL, Zipes, DP, Libby P, Bonow RO, editors. Braunwald's heart disease, 10th edn, Vol. 1. Philadelphia: Saunders, 2015; 429-453.

25. Noordegraaf AV, Westerhof BE, Westerhof N. The relationship between the right ventricle and its load in pulmonary hypertension. J Am Coll Cardiol 2017; 69: 236-243.

26. Svetlichnaya J, Janmohammed M, De Marco T. Special situations in pulmonary hypertension: Pregnancy and right ventricular failure. Cardiol Clin 2016; 34: 473-487.

27. Gomez A, Bialostozky D, Zajarias A, Santos E, Palomar A, Martínez ML, et al. Right ventricular ischemia in patients with primary pulmonary hypertension. J Am Coll Cardiol 2001; 38: $1137-1142$.

28. Oikawa M, Kagaya Y, Otani H, Sakuma M, Demachi J, Suzuki $\mathrm{J}$, et al. Increased [18F]fluorodeoxyglucose accumulation in right ventricular free wall in patients with pulmonary hypertension and the effect of epoprostenol. J Am Coll Cardiol 2005; 45: 1849-1855.

29. Strauer BE. Myocardial oxygen consumption in chronic heart disease: Role of wall stress, hypertrophy and coronary reserve. Am J Cardiol 1979; 44: 730-740.

30. Wong YY, Ruiter G, Lubberink M, Raijmakers PG, Knaapen $\mathrm{P}$, Marcus JT, et al. Right ventricular failure in idiopathic pulmonary arterial hypertension is associated with inefficient myocardial oxygen utilization. Circ Heart Fail 2011; 4: 700-706.

31. Quaife RA, Chen MY, Lynch D, Badesch DB, Groves BM, Wolfel E, et al. Importance of right ventricular end-systolic regional wall stress in idiopathic pulmonary arterial hypertension: A new method for estimation of right ventricular wall stress. Eur J Med Res 2006; 11: 214-220.

32. Mauritz GJ, Noordegraaf AV, Kind T, Surie S, Kloek JJ, Bresser $\mathrm{P}$, et al. Pulmonary endarterectomy normalizes interventricular dyssynchrony and right ventricular systolic wall stress. $J$ Cardiovasc Magn Reson 2012; 14: 5.

33. Noordegraaf AV, Westerhof N. Right ventricular ejection fraction and NT-proBNP are both indicators of wall stress in pulmonary hypertension. Eur Respir J 2007; 29: 622-623.

34. Wiese S, Breyer T, Dragu A, Wakili R, Burkard T, SchmidtSchweda S, et al. Gene expression of brain natriuretic peptide in isolated atrial and ventricular human myocardium: Influence of angiotensin II and diastolic fiber length. Circulation 2000; 102: $3074-3079$. 